\title{
An Experimental Approach to Validate Damage Evolution Laws for Brittle Materials
}

\author{
E. Strassburger, H. Senf, C. Denoual*, P. Riou* and C. Cottenot* \\ Fraunhofer-Institut für Kurzzeitdynamik, Ernst-Mach-Institut (EMI), Hauptstrasse 18, \\ 79576 Weil am Rhein, Germany \\ * DGA/CREA, Département Matériaux en Conditions Sévères, 16 bis, avenue Prieur de la Côte d'Or, \\ 94114 Arcueil cedex, France
}

\begin{abstract}
The understanding of damage initiation and evolution mechanisms is essential to model projectile penetration into ceramics. Two original test configurations have been developed to visualize, in real time, the initiation and propagation of damage. Results obtained are adaptable to a more conventional armour configuration in which no real-time visualizations can be done. An anisotropic model for damage initiation and evolution is presented and experimental results are analyzed and compared to those numerically obtained.

Résumé. Pour modéliser la pénétration d'un projectile dans une cible en céramique, il est au préalable nécessaire de comprendre les mécanismes d'initiation et d'évolution de l'endommagement. Deux configurations d'essais originales ont été développées afin de pouvoir visualiser en temps réel l'apparition et la propagation de l'endommagement. Les résultats ainsi obtenus sont tout à fait transposables à une configuration de blindage plus conventionnelle où aucune visualisation n'est possible. Les résultats expérimentaux sont analysés et comparés à ceux obtenus numériquement à l'aide d'un modèle d'endommagement anisotrope des céramiques.
\end{abstract}

\section{INTRODUCTION}

Modern lightweight armour includes in most cases a layer of ceramic which has the function to break impacting projectiles or erode them significantly. The evaluation and optimization of the ballistic performance of composite armour is a time consuming and expensive process because of the variety of parameters that contribute to the protective strength. For this reason it is desirable to have a numerical tool to help with the design, analysis and evaluation of composite armour. The first step in this direction is to describe the dynamic behavior of the single materials correctly. It is well known that during impact of projectiles on brittle materials, such as ceramics, high stress waves are initiated, which lead to a fragmentation of the material within a cone in front of the projectile [1,2]. The generation of damage during the first microseconds is a major process prior to penetration of the projectile. A detailed knowledge of the fragmentation process is the basis for a realistic modelling of the impact damage in the ceramic. A comparison of the fracture patterns found after impact in a realistic armour configuration and the fracture patterns observed during impact by means of an edge-on impact configuration (see Fig. 1) reveals many similarities. Therefore the edge-on impact can be used to validate damage description and evolution law (e.g. Fig. 2a).

\section{EXPERIMENTAL METHODS}

To visualize the fragmentation during impact, experimental methods were developed at the Ernst-Mach-Institut (EMI) and at the Centre de Recherches et d'Études d'Arcueil (CREA), as presented in Fig. 2. In both methods a high-speed camera was employed in order to determine the time of the onset of fragmentation, the fracture patterns and velocities. Different specimen geometries and different regimes of loading were chosen in both institutes. While the investigations at EMI focused on the development of the fracture patterns and measurements of crack front velocities during the first $10 \mu$ s after impact, the experiments at CREA were designed for the detection of the onset of fracture and the measurement of the stress pulse generated by the impacting projectile. 

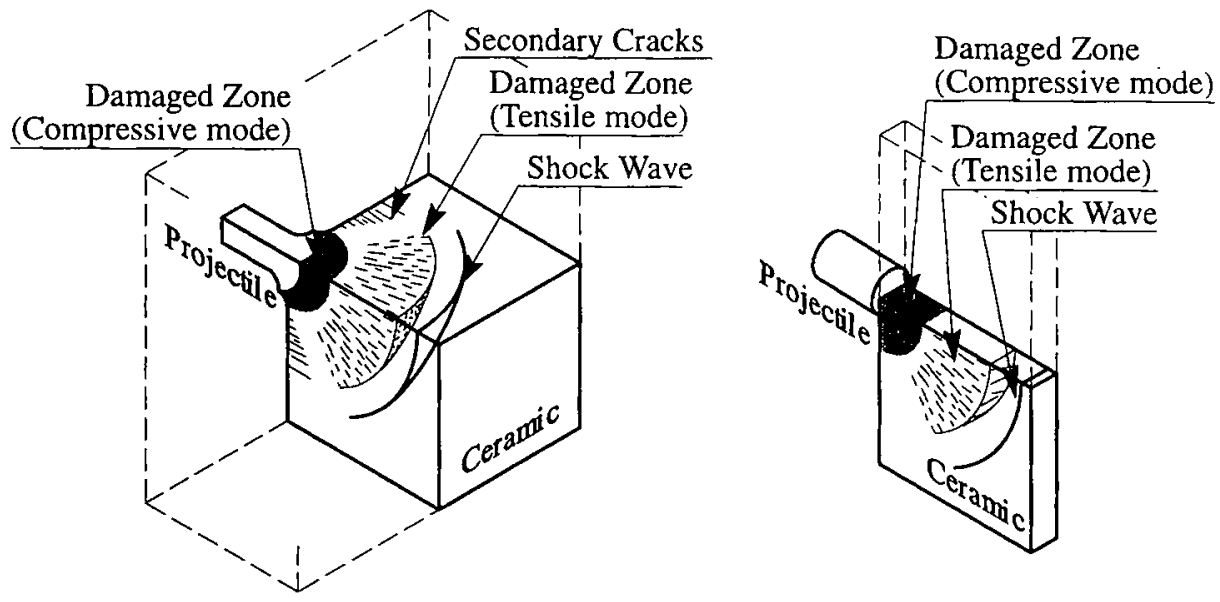

Fig. 1. Morphology of damage in a real configuration and in an edge-on impact specimen.
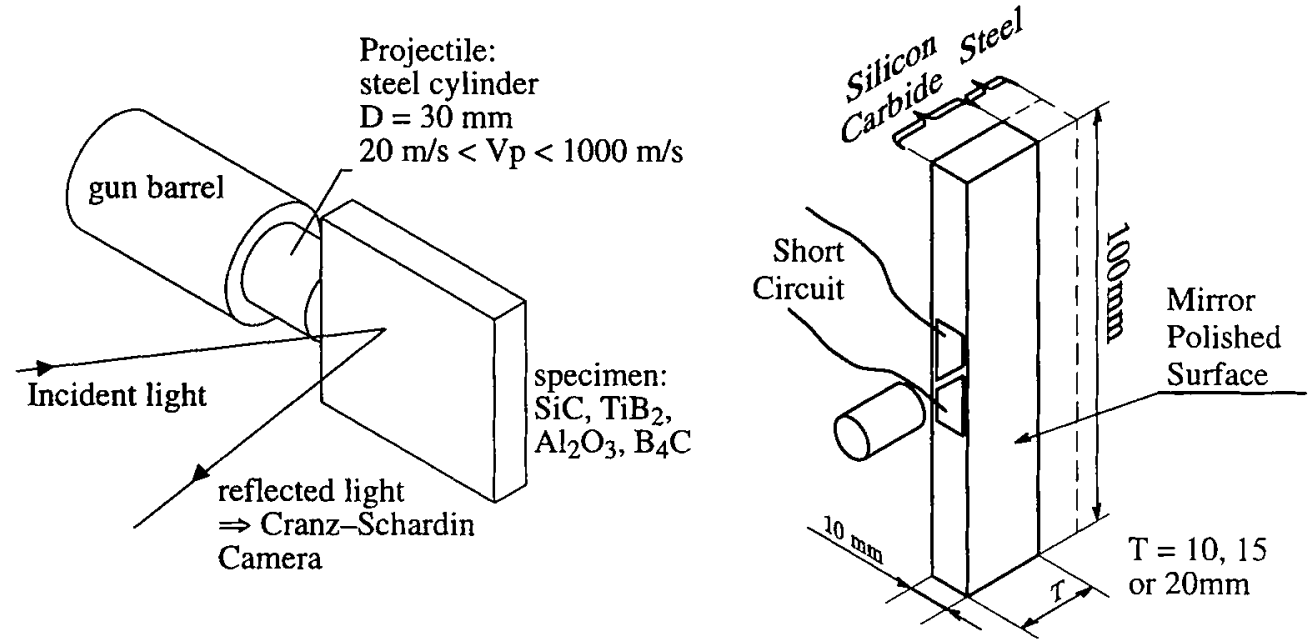

Fig. 2. The Edge-On Impact configuration (a) and the beam configuration (b).

\subsection{Edge-on impact (EOI) tests}

Ceramic plates were impacted with steel cylinders at one edge and the fracture propagation was observed by means of a Cranz-Schardin high speed camera. This type of configuration was used by Hornemann $e t a l$. [3] in order to observe fracture nucleation in glass and applied to ceramics by Winkler and Senf [4]. In the study reported here the dimensions of the specimens were $100 \mathrm{~mm} \times 100 \mathrm{~mm} \times 10 \mathrm{~mm}$. The projectiles had a diameter of $30 \mathrm{~mm}$ and a length of $23 \mathrm{~mm}$. A schematic of the experimental configuration is shown in Fig. 2a. The impact velocity was varied in the range from $20 \mathrm{~m} / \mathrm{s}$ to $1000 \mathrm{~m} / \mathrm{s}$.

Figure 3a depicts one photograph, taken out of a series of twenty pictures of one experiment, where a SiC-B specimen (manufactured by CERCOM Company, USA) was impacted at $513 \mathrm{~m} / \mathrm{s}$. The photograph shows the fracture pattern at $7 \mu$ s after impact. A detailed description of the observed phenomena with SiC and other ceramics was given in [5]. Comparisons of the high-speed photographs with reassembled specimens and experiments with simultaneous high-specd photography of both sides of the specimens have demonstrated that the observed cracks are bulk cracks. 

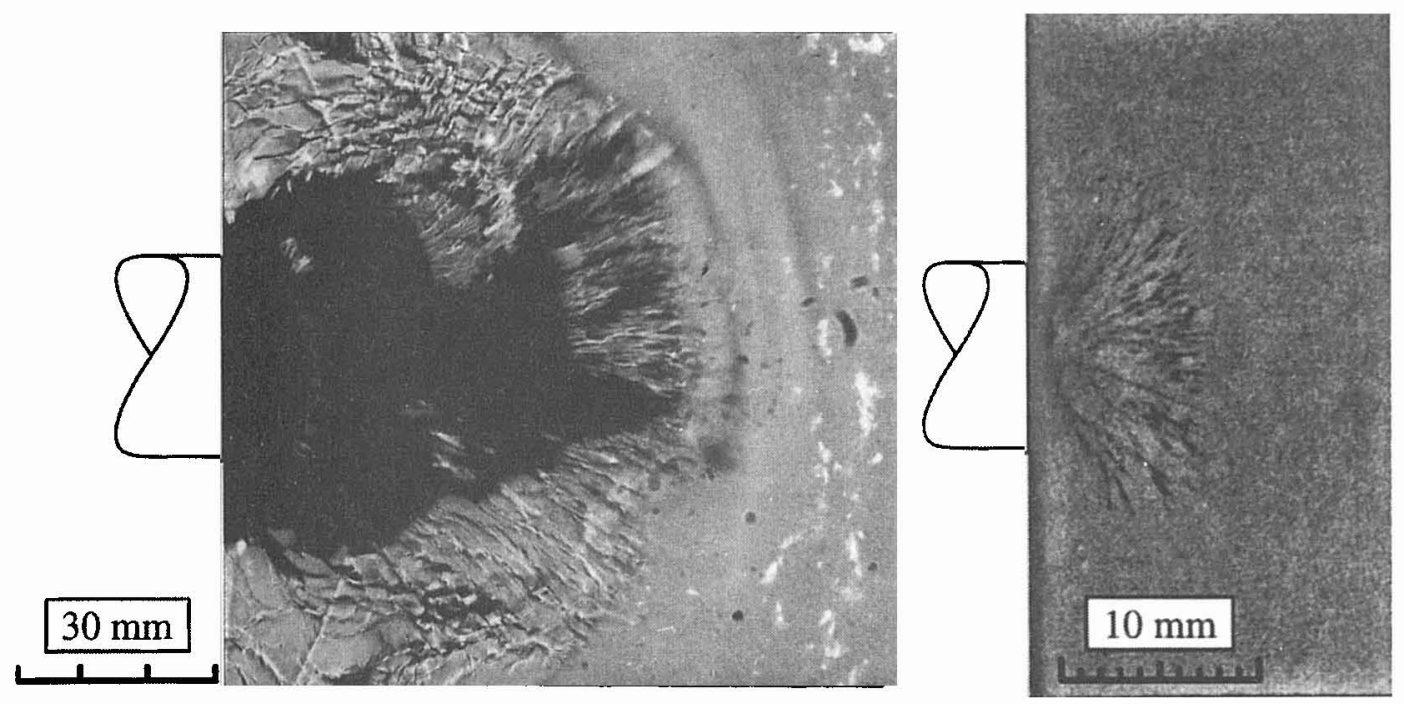

Fig. 3. A typical result of EOI (a) and beam test (b)

This experimental technique can help to characterize ceramics by macroscopic fracture patterns, crack front velocities and single crack velocities as a function of impact velocity.

\subsection{Beam impact test}

A similar method has been developed and adapted to a 'beam' impact test configuration [6]. The ceramic target presents one mirror polished face illuminated by a flash and a high-speed camera records the reflected light (see Fig. 2b). A Nitrogen gas gun launches a steel cylinder ( $11 \mathrm{~mm}$ in diameter and $20 \mathrm{~mm}$ in length) which impacts a confined or unconfined SiC 'beam' with a velocity ranging from 100 to $350 \mathrm{~m} / \mathrm{s}$. The 'beam' dimensions are $100 \mathrm{~mm} \times 10 \mathrm{~mm} \times \mathrm{T}$ where the thickness ( $\mathrm{T}$ ) is equal to 15 or $20 \mathrm{~mm}$.

To obtain interesting data, it is necessary to shoot the first picture as soon as possible after the impact. A contact on the front face of the ceramic beam target is used to trigger the camera. Nevertheless, a triggering time of $0.9 \mu$ s between the impact and the first picture is present. The high-speed camera used for this study is an Imacon 790 which is able to take eight to twelve pictures. Considering the ceramic sample thickness and the crack velocities, at least one half micro-second interframe time is needed. The pictures are obtained with a $180 \mathrm{~mm}$ Nikon lens and a classical photographic film. A typical result on French sintered SiC supplied by Céramiques \& Composites is presented on Fig. 3b. The configuration for an unconfined beam sample of $20 \mathrm{~mm}$ thickness which was impacted at $203 \mathrm{~m} / \mathrm{s}$ has already been analyzed [6].

Additional instrumentation such as manganin stress gage and optical extensometry can be used to obtain complementary real time data. In this case, a comparison with numerical results had revealed good agreement and had confirmed the assumptions of the numerical model described below [7].

\section{NUMERICAL SIMULATIONS}

It is usually very difficult to compare with a good accuracy the experimental and computed damage locations because of the lack of data concerning damage during impact. Experiments, conducted with the two configurations presented above, provide results which can be used to check the numerical simulation. Because of the particular geometry of the target, a three dimensional finite element code (EFHYD) produced by ESI has been used. This code is lagrangian, and uses an explicit integration algorithm. 


\subsection{Presentation of the anisotropic model}

The anisotropic description of damage is consistent with the observed radial crack orientations (Fig. 3). Earlier results [8] suggest that only an anisotropic damage description can provide a realistic crack front propagation. The relaxation in tension is described in the framework of the Continuum Damage Mechanics with a variable $D$ equal to 0 for an undamaged material and equal to 1 for a fully broken one. The anisotropic description of damage in the directions of the maximum principal stress can be given by $\sigma_{K}=\bar{\sigma}_{K}\left(1-D_{K}\right)$ (with $\mathrm{K}=\mathrm{I}$, II, III for the first, second and third principal stress), where $\sigma_{K}$ is the macroscopic stress and $\bar{\sigma}_{K}$ the effective (microscopic) stress. Damage initiation occurs in tension when a principal effective stress exceeds a threshold value (given by a three point bending test), leading to crack propagation in a plane perpendicular to the first principal stress. The damage variable is then equal to the ratio between the penny shaped cracks surface and the section of the elementary volume [6]

$$
D_{K}=N_{f} \pi[r(t)]^{2}
$$

where $r(t)$ is the radius of the penny shaped crack and $N_{f}$ the number of flaws per unit surface. In this volume, damage evolution is then governed by the crack velocity. The velocity of the cracks has been chosen according to experimental data obtained with a high speed camera. The developed model describes several different crack net orientations and is therefore able to take into account the anisotropic nature of the observed damage.

\subsection{Numerical approach of Edge on impact test}

Numerical simulations of SiC-B specimens which have been impacted at $185 \mathrm{~m} / \mathrm{s}$ and $513 \mathrm{~m} / \mathrm{s}$ have been performed. A list of physical properties is presented in Table 1. The steel projectile was modelled by an elastic perfectly plastic behavior with a yield stress of $370 \mathrm{MPa}$.

Table 1

\begin{tabular}{ccccc}
\hline Density & $\begin{array}{c}\text { Shear Modulus } \\
(\mathrm{GPa})\end{array}$ & $\begin{array}{c}\text { Bulk Modulus } \\
(\mathrm{GPa})\end{array}$ & $\begin{array}{c}\text { Threshold Stress } \\
(\mathrm{MPa})\end{array}$ & $\begin{array}{c}\text { Crack Velocity } \\
(\mathrm{m} / \mathrm{s})\end{array}$ \\
\hline 3.18 & 195 & 223 & 523 & 4000 \\
\hline
\end{tabular}

The first case investigated was an impact at $513 \mathrm{~m} / \mathrm{s}$ for which the experimental result was presented above in Fig. 3a. As the French sintered SiC and Cercom SiC-B exhibit different microstructures (e.g. SiC-B presents an intergranular phase), the number of nucleated flaws $\left(\mathrm{N}_{f}\right)$ had to be adjusted. In a recent study on SiC-B which was impacted at $1800 \mathrm{~m} / \mathrm{s}$, Rajendran [9] had proposed to use an $\mathrm{N}_{\mathrm{f}}$ of the order of $10^{9} \mathrm{~m}^{-3}$. Three cases have been investigated here, where values of $\mathrm{N}_{\mathrm{f}}$ of this order of magnitude were chosen. The results are presented in Fig. 4. It can be recognized that small variations of $\mathrm{N}_{\mathrm{f}}$ strongly influence the numerical damage pattern. The first value with $\mathrm{N}_{\mathrm{f}}=0.5 \times 10^{9} \mathrm{~m}^{-3}$ (see Fig. 4a) leads to a diffuse damage. With an increase of $\mathrm{N}_{\mathrm{f}}$ to $0.75 \times 10^{9} \mathrm{~m}^{-3}$, damage localization seems to appear (Fig. $4 \mathrm{~b}$ ), and the numerical damage pattern is in good agreement with the experimental results. For an $\mathrm{N}_{\mathrm{f}}$ value of $2.10^{9} \mathrm{~m}^{-3}$ (see Fig. 4c), damage is localized in thin corridors. Moreover, for the highest value of $\mathrm{N}_{f}$, a mesh dependence for damage localization is observed. These results point out the fact that $\mathrm{N}_{\mathrm{f}}$ has to be adjusted with the impact velocity.

The second case examined was an impact at $185 \mathrm{~m} / \mathrm{s}$. In this case, the damage was mainly localized in several corridors as presented in Fig. 5. This aspect, with corridors number and position was well reproduced by the numerical simulation using an $\mathrm{N}_{\mathrm{f}}$ value of 0.75 (equal to the one used for $513 \mathrm{~m} / \mathrm{s}$ ). It was to be mentioned that the black area ahead of the projectile may result from a tilt of the polished ceramic surface and is probably not damaged in tension. 


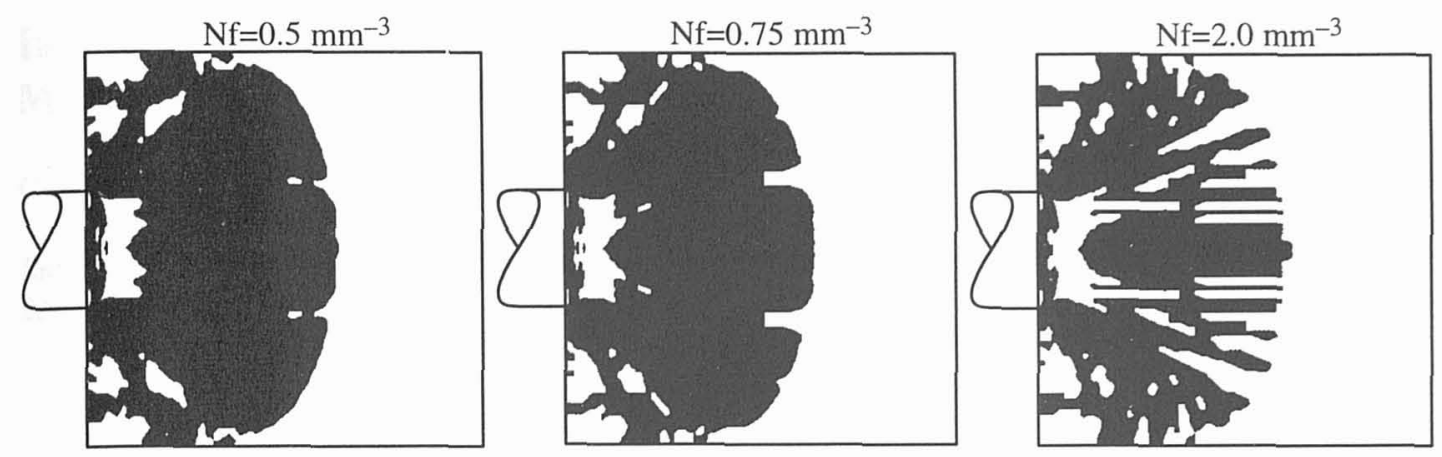

Fig $4 a, 4 b, 4 c$. Numerical simulations of EOI with an increasing number of activated flaws. The material is broken in the black zones $(D>0.5)$ $(V i=513 \mathrm{~m} / \mathrm{s}-$ time $=7 \mu \mathrm{s})$.
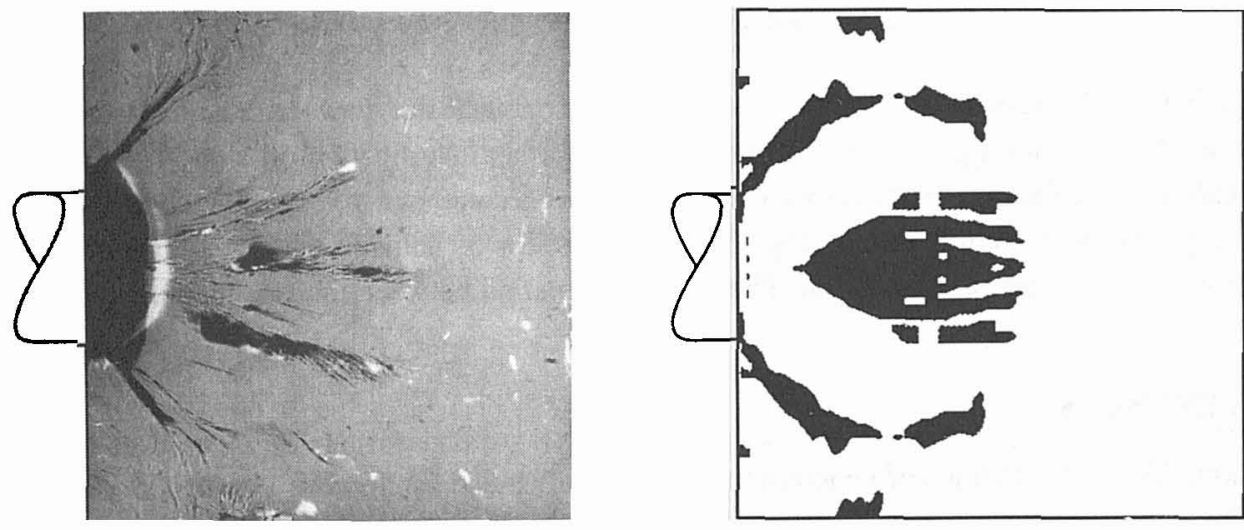

Fig. 5a Experimental and numerical damage pattern comparison $(V i=185 \mathrm{~m} / \mathrm{s}-$ time $=7 \mu \mathrm{s})$.

It is interesting to observe that for $\mathrm{SiC}-\mathrm{B}$, the $\mathrm{N}_{\mathrm{f}}$ value seems to be not affected by the impact velocity. However, $\mathrm{N}_{\mathrm{f}}$ is influenced by ceramic microstructure because for French $\mathrm{SiC}$ the best agreement requires a $\mathrm{N}_{\mathrm{f}}$ value of $2.10^{9} \mathrm{~m}^{-3}$.

A comparison of the experimental and simulated crack front velocities is shown in Fig. 6 for impact velocities ranging from 150 to $640 \mathrm{~m} / \mathrm{s}$. One can notice that the crack front velocity decreases for a decreasing impact velocity down to $370 \mathrm{~m} / \mathrm{s}$. For velocities less than this threshold, damage becomes localized in thinner and thinner corridors as the velocity decreases. Therefor, the energy used by the fracture mechanisms is also localized and makes the damage generation easier so that the crack velocities do not decrease down to an impact velocity of $220 \mathrm{~m} / \mathrm{s}$. This point is confirmed by the numerical simulations which are in good agreement with the experimental results when the impact velocity ranges from 185 to $640 \mathrm{~m} / \mathrm{s}$. For an impact velocity less than $185 \mathrm{~m} / \mathrm{s}$, the numerical simulations become mesh-dependent and do not allow a good agreement with the experimental results.

\section{CONCLUSIONS}

Edge on impact and beam impact configuration are proved to be an appropriate experimental means for the validation of damage evolution laws. The results of numerical simulations using the proposed anisotropic damage are in satisfactory agreement with the experimental results with respect to the fracture patterns and the direction of fracture propagation. However, there are still several points such as the evolution of the 


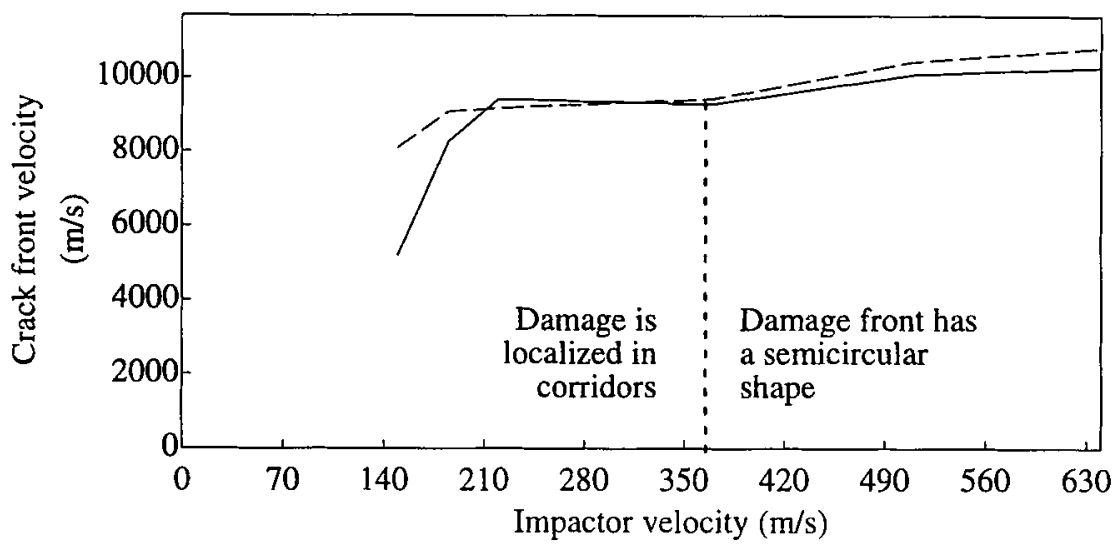

Fig. 6. Damage propagation velocities for EOI

activated flaws with stress rate, the influence of microstructure on nucleated flaws and the influence of the compression behavior for high compressive stresses that need further investigations in order to get a deeper understanding of the damage mechanisms. CREA and EMI have a common interest in these investigations and the expertise and facilities are complementary with respect to ballistic testing, micro-structural investigations and numerical simulation. Therefore, a collaboration between the two institutes has been initiated.

\section{REFERENCES}

[1] Wilkins M.L., "Mechanics of Penetration and Perforation", Int. J. Engng. Sci., 16, pp. 793-807, 1978.

[2] Shockey D.A., Marchand A.H., Skaggs S.R., Cort G.E., Burkett M.W., Parker R., Int. J. Impact Eng., Vol. 9, No. 3, (1990)

[3] Hornemann U., Rothenhäusler H., Senf H., Kalthoff J.F., Winkler S., "Experimental investigation of wave and fracture propagation in glass slabs loaded by steel cylinders at high impact velocities", Inst. Phys. Conf. Ser. No. 70, $3^{\text {rd }}$ Conf. Mech. Prop. High Rates of Strain, Oxford, 1984

[4] Winkler S., Senf H., Rothenhäusler H., "Wave and fracture phenomena in impacted ceramics", Fraunhofer-Institut für Kurzzeitdynamik, Weil am Rhein, EMI-Report V 5/89, 1989

[5] Straßburger E., Senf H., Rothenhäusler H., "Fracture propagation during impact in three types of ceramics", Proc. of EURO DYMAT 94, Journal de Physique IV, C8, Vol. 4, pp. 653-658, 1994

[6] Riou P. “Contribution à l'étude de l'endommagement du Carbure de Silicium lors d'un impact de basse énegie : application aux blindages", PhD Dissertation (1996), Univ. Bordeaux I.

[7] Riou P., Cottenot C.E., Boussuge M. "Steel Rod Impact on Silicon Carbide Beams: Experiments and Anisotropic Model of Damage" (1996). Proc. of SUSI 96, Computational Mechanics Publications, pp 533-543.

[8] Denoual C., Cottenot C.E., Hild F. "On the identification of Damage During Impact of a Ceramic by a Hard Steel Projectile", (1996). Proc. of the $16^{\text {th }}$ Ballistic Symp., pp 541-550.

[9] Rajandran A. M., Grove D. J., "Modeling the shock response of silicon Carbide, Boron Carbide and Titanium Diboride", Int. J. Impact Engng., (1996) 18, 6, pp 611-631. 